\title{
Comparison of Emphasis Point Towards Marketing Strategies Between Pepsi \& Coca-Cola
}

\author{
Yueqian Dai
}

SMIC Private School, Shanghai, 200082 China

*Corresponding author. Email: angela@cas-harbour.org

\begin{abstract}
As majority of people become more and more concerned about their health, the demand for soft drinks becomes less and less. Despite this relative inferior position in the soft drinks market, Coca-Cola has maintained its dominance for a certain long period; while its rival, Pepsi, has seen its profits decline. This paper studies and analyzes the basic marketing strategies of these two famous soft drink brands, which have been in a rivalry for a long time, including the comparison and difference of IMC (Integrated Marketing Communication), logo design and their brand influence, and the particularity of the target market. Through in-depth analysis, the author analyzed how the two companies compete for their position in the beverage market from their respective perspectives. Based on a series of marketing strategies related to Pepsi and Coca-Cola's market, consumer groups, and endorsements as well as the previous research, and through further analysis, this paper concludes some obvious differences in the basic marketing methods used by the two companies in selling soft drinks. In addition, based on the collected data, analysis and evaluation, and according to the trend of Pepsi cola and Coca-Cola in better sales of drinks, the future marketing strategies of Pepsi cola and Coca-Cola are briefly predicted. More research are needed for future development, and it is also desirable to make further follow-up research on the basis of this research report to get more precise and insightful results or evaluations.
\end{abstract}

Keywords: Coca-Cola, Pepsi, Marketing strategy, Beverage market, IMCs

\section{INTRODUCTION}

In recent years, with health awareness of people increasing year by year, the demand for soft drinks is declining year by year, and more and more people are choosing healthier and less sugary drinks instead of carbonated ones. In a market that is fatal to soft drinks, Coca-Cola has long maintained a relative dominance in the market, while most of its competitors, including Pepsi, have seen their sales slide. In fact, the battle between the two beverage companies has never stopped, despite the fact that they are both well known among beverage companies around the world. According to the data and analysis, this report, from the perspective of the two companies themselves, is to study the competition between sales, market share, product contrast, and how effectively they apply their own marketing strategy to promote sales and enhance people's awareness and identification of their own brands. Through some in-depth research and analysis, it is concluded that there are obvious differences between Coca-Cola and Pepsi Cola in logo designs and several factors of IMCs.

\section{THE DEVELOPMENT OF LOGO DESIGN BETWEEN PEPSI \& COCA-COLA}

\subsection{Change of Pepsi's Logo}

Pepsi's classic global icon in the soft-drink market now has actually undergone several major changes. Pepsi company began to attach importance to the design of logo and font since 1898, and designed its name "Pepsi" according to the design concept of red curve. Pepsi's tricolor pattern stands out, and the color does serve as a powerful memory for soft drink consumers or the Pepsi brand. For the fifth time since 1950, Pepsi has redesigned its logo to include a three-color icon. An old glass bottle with red, white and blue squares at the top was inspired by the Sumerian character for "water". "PEPSI" stands for pepsin, which is actually a substance that stimulates taste and promotes health, possibly coincidentally with the company's subsequent marketing strategy. By 1962, Pepsi had removed the tilt of the cap to make it appear in the most intuitive way possible. The change made the word "Pepsi" more readable to consumers, which meant it was easier for the public to remember. In fact, it was 
also defined as the first Pepsi logo trend to appear simplified. During the subsequent changes from 1973 to 2008, there was no significant trend change in Pepsi logo design. By 2008, the PepsiCo brand had changed significantly in the way people thought about its logo design - the combination of ICONS and letters became a left-right typography, with the tricolor ball on the left and the "PEPSI" on the right. In an even bigger change, PEPSI has replaced all five letters of its "PEPSI" with a lowercase "PEPSI" to present to the public, once again demonstrating that its logo design is going in the direction of simplicity. The latest change came in 2014, when Pepsi finally removed the borders of the tricolor spheres, leaving only a simple Mosaic of red, white and blue blocks, taking its icon design to a new, more simplified level [1].

\subsection{Change of Coca-Cola's Logo}

In 1887, a year after it came to market, coke's founders put a lot of effort into branding, leading to the brand's first distinctive logo design, a delicate look designed by Frank Mason Robinson that is still in common use today. With the exception of a single unsuccessful fairy tale font change in 1890, the Coca-Cola Company has maintained the original design, gradually making it a classic icon rooted in the hearts of consumers. This unchanging style reinforces the concepts of "classic" and "rigid" and occupies an unshakable position among the most loyal fans and consumers of music. From seeing the logo to thinking about the brand to increasing the probability of consumption, this chain reaction actually helps the Coca-Cola company to promote any beverage under its brand, because people automatically think that Coca-Cola is the most classic and authentic, and natural is the best. Unlike Pepsi, the Coca-Cola logo or color does not have an extended meaning. However, it may be wise, because undefined means that it is not bound by any concept or meaning, which means it is not represented or represented but just Coca-Cola itself [2].

\subsection{Comparison of Logo Designs between Pepsi and Coca-Cola}

Both Coca-Cola and Pepsi have a strong desire to distinguish themselves from other soft drinks companies in order to increase their visibility without being confused by consumers. Because they themselves clearly understand that the competition between the world's two largest soft-drink companies is a given and will continue indefinitely. Yet when it comes to choosing how to represent themselves, the two companies clearly have different priorities. The overall trend in Pepsi icon design is an inevitable result of simplicity. First, the word "cola" was removed in 1962, making Pepsi less like its main rival, Coca-Cola. With more distinctive characters in its name, Pepsi has been able to create its own brand and tell its own story rather than just being an imitator. After the first simplification in 1973, the Pepsi logo was further simplified in 2008, leaving only the simplest color combinations and lowercase fonts. Coca-Cola, by contrast, has made only one major change to its logo, the first unique handwriting change. It was a wise decision that Coca-Cola could not have foreseen, even when they designed it. This trademark change allowed it to compete successfully with many talented competitors in the beverage market. To this day, they have adopted and followed the special design on the red front, making it distinctive, people easily remember the logo on the red background and white letters, and because of its special design associated with Coca-Cola. Coca-Cola pays attention to its uniqueness and exclusivity in marketing, and the design of its logo is a powerful tool to stabilize its position in the soft drink market. As it is expected, Coca Cola has become the classic taste in most people's mind, because of its originality and purity, it is easy for people to choose to buy it over other brands, which usually means close to the best.

\section{IMCS OF PEPSI}

The utilization of lover brand archetype is what Pepsi long relied on. The use of celebrity, which is a prototype of lover brand archetype, has always given Pepsi an opportunity to create a "hot topic", whether based on musicians, sports stars, or any other celebrity. This is not only because of the benefits of the celebrity's own pulling products, but also because there are other motivations to promote the theme of fermentation, making the celebrity and the products they need to promote more influential. Usually, celebrity effect can arouse the emotion and enthusiasm of a specific audience group, which means a large fan group can arouse the loyalty of these consumers, and finally achieve the purpose of promoting sales. Pepsi has long been known for its celebrity hype, which in itself puts a premium on sports stars' fans, who often number in the millions. In a typical football season, four million fans take part in sporting events outside the four football clubs.

Soft drink is more likely to be a bad product as it is an economic term that describes a product in which demand drops when people's incomes rise. Therefore, the declining demand of more and more customers for sugary soft drinks and the increasing demand for low-sugar or diet drinks as substitutes are bound to become the most fundamental future trend of the beverage market. In recent years, as people's pursuit of health has become more and more intense, the global public demand for low-sugar or zero-sugar drinks is also increasing. This has undoubtedly had a certain impact on the whole Coca-Cola market. Since Pepsi and coke have been substitutes for each other for the majority of ordinary consumers, those who have not formed an inherent habit of drinking a particular type of soft drink 
have an obligation, or must, to keep prices within the same range at all times.

\subsection{Use of Social Media}

The new use of social media has proved to be quite ambitious and effective in the overall development of Pepsi soft drinks. With the practical application of new social media, Pepsi can further develop the youth market as the youth is always the biggest potential market in the future, because each young generation represents the development space and potential market. There is solid evidence and data to prove the widespread and positive impact of Pepsi's new social media (Twitter, hashtag). By holding these activities and publicity activities on the Internet, Pepsi often has active contact with "netizens", especially young consumers, with the purpose of promotion, which naturally reaches the ultimate purpose of publicity. Their potential consumers, those who are interested in certain activities online, are quick to follow the latest and hottest products, and once Pepsi gets that attention, it will spread and spread faster than any other medium. However, always maintaining a highly sensitive and correct opinion direction is not an easy task. Pepsi needs to be aware of and sensitive to the latest news or trend models or stars, who may need to keep an eye on or be exposed to the hottest events [3].

\subsection{Propaganda for the Concept of Health}

One of PepsiCo's most competitive marketing strategies in the future is likely to be based on the concept of health. With increasing awareness of health, more and more consumers are choosing healthy, low-sugar, non-carbonated drinks. Therefore, adopting this concept as the main direction of promotion is a fairly accurate decision in both ethical and commercial aspects. The Lipton brand is the most influential brand under Pepsi, which represents the main promotion concept of Pepsi based on health. Tea itself is a good health drink in people's Daily life. Lipton bottled tea, packaged tea and other tea-related products sold in supermarkets or online meet consumers' demand for these healthy drinks. Studies have shown that drinking Lipton tea has 32 benefits, including preventing cancer, increasing fluid intake, and improving the immune system. The health benefits of Lipton tea add positive value to maintaining health and well-being. The Pepsi brand has arguably done a better job than Coca-Cola at promoting healthy drinks such as tea. Moreover, in a health-conscious world, more and more people are choosing tea over sugary soft drinks, which has naturally helped pepsi-Lipton boost sales in the harsh soda market. "The big growth that we've observed across our beverage brands has been around no sugar" explained Natalie Redford, marketing director of PepsiCo UK. "We're really unlocking what that means." This shift is being seen around the globe. Although coke has a larger market share, the ratio between Pepsi and coke is not immutable, as people's taste for healthy eating is changing more and more clearly. People who drink healthier drinks, which means less sugar, or tend to drink tea, opt for more pepsi-branded healthy drinks, such as Pepsi One, Amp Energy Sugar Free, Aquafina FlavorSplash, Light Vanilla. It still has many developing space for develop more diet drinks in the future market for an even broader range of customers [3].

\subsection{The Brand Spirit of Liberty and Specialization}

Pepsi's latest slogan, "This is what I like," emphasizes and aims at consumers who want to live loudly and differently. Pepsi's target consumers are likely to be those who have always had a unique or unusual lifestyle or lifestyle, as well as those who have special preferences or personalities, especially those who have a tendency to assert their individuality. This kind of excite-seeking and adventurous personality is exactly the message Pepsi wants to send to the masses. Because they are not afraid of being judged positively or negatively by others, they are likely to live more freely or with more tolerance. Because they do not care, they can always focus more on what they are doing or the dream they are pursuing without thinking about others. Pepsi-cola ACTS as a powerful supporter of this concept, bringing together people with the same interests and spurting out even more powerful forces with Pepsi's blessing and support. This indoctrination of ideas and ideas will eventually translate into consumers' desire to buy Pepsi.

\section{IMCS OF COCA-COLA}

Coca-Cola's slogan "Sharing" is an important role and contributes significantly to the overall prosperity of the brand spirit. With its strong sense of interaction to share happiness with family and friends, Coca Cola has won a large number of consumers impressed by its psychological application for marketing purposes. Their IMC has played an effective role in the interactive communication of brand spirit, which has made its direct marketing a very important part of the whole IMC. For example, before a movie is released, some theaters will show Coca-Cola's ads on podcasts to encourage viewers, or at least remind them, to recognize the famous brand. They strengthen the concept that their own brand is dominant in the Coke market, help the audience remember and think of their own brand all the time, make it rooted in the hearts of most people for a long time, and maintain a positive impression of the brand, thus promoting the sales of the brand, and thus having a greater impact. In addition, the initial volume of Coca-Cola itself is very large, which means that people can see its billboards anytime, anywhere, without having to look very hard. This marketing strategy may not be very innovative, but it is still a good example of its 
inclusive broadcasting capability and reinforces the industry leader that Coca-Cola has remained in the soft drinks market [5].

\subsection{Close Interaction with Customers}

Coca-Cola believes that interaction with its customer base is an important strategy to sustain consumers. Since 2015, the company has held "Share Coke" activities. By allowing customers to put their names on their bottles, Coca-Cola draws people to its brand and builds strong bonds with its customers, customizing them for an average price of $\$ 7$ per person. What is more, they also prepared 200 common names for consumers to choose from. By putting their name on the bottle, consumers can have a natural connection with the brand, a sense of being a part of Coca-Cola or being immersed in it, so it is easy to increase the loyalty of consumers to the brand. Looking back at the history of Coca-Cola's slogan, it is easy to see that the words most frequently mentioned are related to "happiness," "freshness" and "enjoyment." This brand keeps its spirit simple and easy to understand, which is easily understood and resonated by most consumer groups, thus making it more popular. Consumers always have a consensus and sense of identity for Coca-Cola [1].

\subsection{The Absolute Popularity}

People may not have noticed that Coca-Cola is considered to be one of the five best examples of IMC. Coca-Cola's classic brand, a trademark style with a red background and a specific white font, has 94 percent global recognition. In fact, "Coca-Cola" is one of the three most common words in most languages in the world today. Such statistics are enough to show that the popularity of Coca-Cola in the industry and even outside the industry is extremely difficult to be surpassed by other brands.

\subsection{Inspiration of the Goodness of Human Nature}

After receiving a patent in 1915, Coca-Cola first decided to create a bottle design that was "so unique you could feel it in the dark." An Indiana company used a $\$ 500$ creative prize to design the bean's curve, a design that gave the Coca-Cola bottle real recognition at the time. Coca-Cola promoted its brand using naive archetypes-people who usually only see the good in people. This kind of marketing strategy is used to finding the positive side of people's kindness and morality. In addition, the basic principle of its value light is to achieve harmony as the ultimate goal. For customers who have a preference for this brand prototype, the solution to the problem is simple. Most of them have a simple mind and way of thinking and have a simple way to deal with any dilemma. This is hardly a good thing when they are exposed to the real world, full of power and harsh conditions. However, it is also their simple thinking that makes them more likely to be happy than those who are complicated, because they do not over-think, they will not have excessive worry, so they can solve any difficulties in life with ease and no pressure. With such a simple mind, people with such things usually have a wider and more tolerant mind, easy to be moved and moved, easy to get happiness, and they simply believe in the goodness of human nature deep in their hearts.

Coca-Cola is classified as a "magician's brand", meaning that dreams come true and dreams come true. In other words, it considers the concepts of realization and idealism to be meaningful. For any kind of deformity, imperfection and incompetence, the "magicians" of these brands under this definition always believe that people, or humans, can overcome all difficulties and use any tool to achieve or create any kind of success and happiness. This vein of thought entity gives all things infinite possibilities, and gives people the strength and determination to deal with hardships and difficulties. With the help of this way of promotion, Coca Cola's promotion conveys the message that "happiness is not difficult to possess" through "opening happiness". Once the coke bottle is opened, the sense of happiness and satisfaction will be held in the hand and drunk into the mouth, becoming a thing that is no longer difficult to achieve. The world was created for you to overcome and achieve happiness, and the idea that Coca-Cola conveys really enhances one's ambition and ability to accomplish anything. Among family members, between two friends, between brothers, between boys and girls, this universally recognized relationship always brings positive, deep emotions, and is easily understood and understood by most people [4].

\section{COMPARISON OF IMCS BETWEEN PEPSI AND COCA-COLA}

The use of archetypes can often help a brand convey or transform its abstract spiritual culture into a message that can be understood by a majority of its target audience. A good and effective brand prototype tends to take people into their mode of thinking, enabling their customers fully understand their brand concept, and thus easily let people resort to emotional and their products in a certain extent of emotional resonance. This will eventually achieve the goal of waking up a sense of belonging to this brand. It is worth noting that both Pepsi and coke have chosen a sensible brand prototype to promote. In fact, with Pepsi and coke, different people find their own group and gain a sense of belonging.

Indeed, in terms of market share, Coca-Cola is better than Pepsi, with about $10 \%$ more of the overall carbonated beverage market than Pepsi. However, this has changed with people's tastes and pursuit of healthy drinks. Coke entered the market seven years before 
Pepsi, which meant it had the best competitive position in the carbonated beverage market and definitely dominated the soft drink market more easily than its competitors. However, people are becoming more health-conscious in recent years, and carbonated drinks such as Colas, full of sugar and unhealthy dietary elements, are losing their advantage as a top priority when consumed. In this case, if the company does not change its marketing strategy, any major soft drink company is likely to face the problem that most carbonated drink companies now face, that is, the sales volume of unhealthy carbonated drinks, including Coke and Sprite, declines, and the consequences are irreversible. By contrast, its arch-rival, Pepsi, changed its marketing strategy in early 2006 through shrewd market observation. The promotion of Lipton tea and its own sales results are a good example. Sales of tea bags and loose-leaf teas exceeded $\$ 1.3$ billion, up 9.4 percent from the same period last year. According to Lipton's sales report, it topped the segment with nearly $\$ 227$ million in sales and a 3.5\% growth rate. That is to say, the overall trend of the tea market is considerably impressive, and the tea under the Pepsi brand has successfully demonstrated a good growth trend for the further development of tea products of various beverage companies and brands. Namely, PepsiCo is likely to take a bigger share of the U.S. and even global beverage market in the future at a time when soft drinks market is weakening and most consumers are increasingly health-conscious year by year [6].

\section{CONCLUSION}

It is an effective use of different archetypes that helps two brands communicate their respective corporate cultures, and once people spontaneously connect and empathize with the brand, the brand specific product archetype effect comes into play. However, it is unreasonable to judge who is higher on the basis that Coca-Cola's current sales and turnover are higher than Pepsi's. With people's taste and pursuit of healthy drinks, carbonated drinks such as Cola are losing their advantage in consumption while Pepsi has the obvious advantage. Under the inevitable trend of carbonated beverage sales decline, Pepsi Cola keenly observed this trend as early as 2006, and then changed its marketing strategy. Conforming to market rules and trends, combining with the actual situation of its own brand, actively meeting the market demand and making corresponding changes in time are the secrets of enduring prosperity of an enterprise. All marketing and advertising strategies serve to increase product sales. In a word, as long as the company is not limited to short-term economic benefits, but to forecast the future market in advance and allow marketing to play a maximum role, then it is possible for the enterprises to achieve long-term stable development [7].

\section{ACKNOWLEDGMENTS}

I wish to express my sincere gratitude to Professor Bernadette Wegenstein, the especialist and advisor of New media Revolution Program for teaching and helping me to be enlightened at this subjects with her academic lectures on principles and theories of the realm of media. My completion of this project could not have been accomplished without the support of Profess Bernadette, my mentor Jane and Teacher Assistant Yujia Cheng. I sincerely express my deep sense of gratitude again.

\section{REFERENCES}

[1] Batyrovich, P., FactPros.comWriter, A., Batyrovich, A., FactPros.comWriter, et al.(2018, September 08). Meaning of Pepsi Logo: What does the shapes and colors symbolize.

[2] Admin. (2020, September 17). Coca-Cola Logo. Retrieved on October 01, 2020, from https://1000logos.net/coca-cola-logo/

[3] Jackson, D., Greg, \& Bella. (2017, September 18). Brand Analysis: Pepsi and The Soft Drink Industry.

[4] Perch, D., \& Darbinyan, M. (2020, July 16). Coca-Cola Target Market. A Case Study. Retrieved on October 01, 2020, from https://thesocialgrabber.com/coca-cola-target-mark et/

[5] Dthotave, (2016, May 21). IMC of COCA-COLA. Retrieved October 01, 2020, from https://mpk732t12016clusterb.wordpress.com/2016 /05/09/imc-of-coca-cola/

[6] LIPTONÂ®. (n.d.). Retrieved on October 01, 2020, from

https://www.pepsicopartners.com/pepsico/en/USD/ PEPSICO-BRANDS/LIPTON\%C2\%AE/c/brand_li pton? source=brand-pepsicobrands

[7] Team, M. (2020, May 13). Integrated Marketing Communications (IMC) Definition, Importance, Example \& Overview: Marketing Dictionary. 